\title{
Effect of robotic gait training on cardiorespiratory system in incomplete spinal cord injury
}

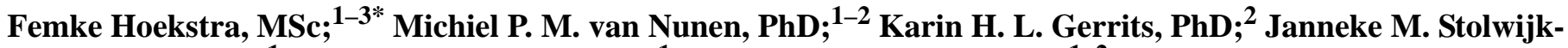 \\ Swüste, MD, PhD; ${ }^{1}$ Martine H. P. Crins, MSc; ${ }^{1}$ Thomas W. J. Janssen, PhD $^{1-2}$ \\ ${ }^{1}$ Amsterdam Rehabilitation Research Center | Reade, Amsterdam, the Netherlands; ${ }^{2}$ Faculty of Human Movement Sci- \\ ences, MOVE Research Institute Amsterdam, VU University Amsterdam, Amsterdam, the Netherlands; ${ }^{3}$ Center for \\ Human Movement Sciences, University of Groningen, University Medical Center Groningen, Groningen, the Netherlands
}

\begin{abstract}
The objectives in this study were to investigate the effect of robot-assisted gait training on cardiorespiratory fitness in subjects with motor incomplete spinal cord injury and document the exercise intensity of robotic walking in comparison with the recommended guidelines. Ten patients followed a 24-session training program with a robotic gait orthosis in addition to physiotherapy sessions completed within 10 to 16 wk. Cardiorespiratory fitness was determined in a graded arm crank exercise test before and after the training program. To assess the intensity of robot-assisted walking, oxygen consumption $\left(\mathrm{VO}_{2}\right)$ and heart rate (HR) were measured during a training session early in and at the end of the training program, and exercise intensity measures (percentage of $\mathrm{VO}_{2}$ reserve $\left[\% \mathrm{VO}_{2} \mathrm{R}\right]$, percentage of $\mathrm{HR}$ reserve [\%HRR], and metabolic equivalents [METs]) were calculated. Whereas no changes were found in peak $\mathrm{VO}_{2}$, the resting and submaximal $\mathrm{HR}$ at a constant work load were significantly lower after training. Most subjects exercised at low intensity $\left(<30 \% \mathrm{VO}_{2} \mathrm{R}\right.$, $<30 \%$ HRR, $<3.0 \mathrm{METs}$ ), and only two subjects exercised at moderate intensity ( $>3.0 \mathrm{METs})$. In spite of the low exercise intensity of the training program and no changes in peak $\mathrm{VO}_{2}$, robot-assisted gait training induced some improvement in cardiorespiratory fitness, as suggested by lower resting and submaximal HR values.
\end{abstract}

Clinical Trial Registration: ISRCTN Register, ISRCTN67827069, "Recovery of Walking Ability Using a Robotic Device"; http://www. controlled-trials.com/ISRCTN67827069
Key words: aerobic training, cardiorespiratory fitness, exercise, exercise intensity, heart rate, locomotor training, oxygen consumption, rehabilitation therapy, robot-assisted gait training, robotic walking, spinal cord injury.

\section{INTRODUCTION}

Physical inactivity is commonly reported in the population with spinal cord injury (SCI) [1] and is a major risk factor for developing cardiovascular disease (CVD) [2-3]. Being physically active reduces the risk of CVD and a

Abbreviations: \%HRR $=$ percentage of heart rate reserve, $\% \dot{\mathrm{VO}}_{2} \mathrm{R}=$ percentage of oxygen consumption reserve, ACSM = American College of Sports Medicine, AIS = American Spinal Injury Association Impairment Scale, BWS = body-weight support, $\mathrm{CVD}=$ cardiovascular disease, $\mathrm{ECG}=$ electrocardiogram, $\mathrm{FES}=$ functional electrical stimulation, $\mathrm{GF}=$ guidance force, $\mathrm{HR}=$ heart rate, $\mathrm{iSCI}=$ incomplete spinal cord injury, $\mathrm{MET}=$ metabolic equivalent, $\mathrm{SCI}=$ spinal cord injury, $\dot{\mathrm{VO}}_{2}=$ oxygen consumption .

*Address all correspondence to Femke Hoekstra, MSc; Center for Human Movement Sciences, University of Groningen, University Medical Center Groningen, Antonius Deusinglaan 1, Sector F, Rm 3216-0219, 9713 AV Groningen, the Netherlands; 31-50-363-6185.

Email: f.hoekstra@umcg.nl http://dx.doi.org/10.1682/JRRD.2012.10.0186 
wide range of other medical conditions such as diabetes and obesity [4-6]. Therefore, interventions to promote physical activity in the population with SCI are becoming increasingly important. Traditional exercise modes to improve physical fitness for the population with SCI are arm exercise in a wheelchair or using an arm ergometer and leg exercise with functional electrical stimulation (FES). However, the prevalence of shoulder pain, mostly as a result of overuse, is very high in wheelchair users [79]. Therefore, an exercise modality without the repetitive use of upper limbs may be preferable. Through use of FES exercise, the large muscles of the legs can be activated, which can lead to a wide range of fitness and health benefits [10-11]. However, about half of the population with SCI have incomplete lesions, which makes the application of FES painful for many of these individuals [12]. As an alternative, robot-assisted gait training with the Lokomat (Hocoma AG; Volketswil, Switzerland) was introduced as a form of aerobic exercise for these individuals with incomplete SCI (iSCI) [13].

The Lokomat is a device consisting of two robotic arms and a treadmill with a body-weight support (BWS) system. The robotic arms can be attached to the patient's legs and the body weight is supported by a BWS system while walking on the treadmill [14-15]. Speed, BWS, and amount of assistance can be adjusted to individual ability in order to create a challenging environment where patients can practice stepping. Most studies investigating robot-assisted gait training in iSCI focused on the effectiveness of improving neurologic and motor function and concluded that it is an appropriate therapy for improving walking ability [16-17]. Although there is some knowledge with regard to the cardiovascular effects of BWS treadmill training with manual assistance $[13,18-21]$, little is documented about the cardiorespiratory effects of robot-assisted gait training.

Promising results with regard to cardiovascular effects of robot-assisted therapy have been reported in the population with SCI [22-25]. A recent cross-sectional study by Jack et al. showed that, with vigorous active participation of patients, a substantial increase in heart rate (HR) and oxygen consumption $\left(\dot{\mathrm{VO}}_{2}\right)$ can be achieved [24]. However, without the voluntary activity of the patient (i.e., passive walking) exercise intensity (HR and $\dot{\mathrm{V}}_{2}$ ) was much lower and probably insufficient to stress the cardiopulmonary system according to the levels of intensity for aerobic training recommended by the American College of Sports Medicine (ACSM).
Recently, through use of more sophisticated controllers of the orthoses, gait patterns during robotic walking are less prescribed, and more variation in the gait pattern is possible. These new controllers allow active participation of patients in the kinematics of locomotion, which may be more effective for motor learning [26-27]. However, the effects on the cardiorespiratory system have not yet been studied. Furthermore, little has been documented about longitudinal changes in cardiopulmonary fitness by Lokomat therapy in patients with SCI [13]. Therefore, this study had two goals. The primary purpose of this study was to investigate the effect of a period of active robot-assisted gait training on cardiopulmonary fitness in subjects with a motor iSCI. The secondary purpose of the study was to document the exercise intensity of robotic walking in comparison with the guidelines recommended by the ACSM for exercise intensity.

\section{METHODS}

\section{Subjects}

Ten subjects with a motor iSCI participated in this study (Table 1). The inclusion criteria were paraplegia or tetraplegia as a result of a motor iSCI (American Spinal Injury Association Impairment Scale [AIS] levels C and D [28]), minimum age of $18 \mathrm{yr}$, height between 150 and $195 \mathrm{~cm}$, and maximum body mass of $115 \mathrm{~kg}$. The limitations to height and body mass were necessary because of the design of the Lokomat device. The exclusion criteria were medical complications such as uncontrolled cardiac dysrhythmia and other unstable cardiovascular problems, severe skeletal problems such as osteoarthritis or recent fractures of the lower limbs, severe cognitive and/or communicative disorders, other neurological and/or psychiatric disorders, severe spasticity, open wounds or unhealed skin, thrombosis, pneumonia, or other problems that make it impossible to properly accomplish the tasks. Information about the type and location of the lesion was obtained through a clinical evaluation by a physician. After a detailed explanation of the purpose and the protocol of the experiments, all subjects signed an informed consent. The study was approved by the ethics committee of the VU University Medical Center Amsterdam.

\section{Study Design}

A single-group pretest-posttest design was used to investigate whether cardiorespiratory fitness improved 
Table 1.

Subject characteristics at baseline.

\begin{tabular}{|c|c|c|c|c|c|c|c|c|}
\hline Subject ${ }^{*}$ & Sex & $\begin{array}{l}\text { Age } \\
\text { (yr) }\end{array}$ & $\begin{array}{l}\text { Height } \\
\text { (cm) }\end{array}$ & $\begin{array}{c}\text { Body Mass } \\
\text { (kg) }\end{array}$ & Lesion Level & $\begin{array}{c}\text { Time Postinjury } \\
\text { (yr) }\end{array}$ & AIS Level & LEMS \\
\hline$\overline{\mathrm{C} 1}$ & $\mathrm{M}$ & 52 & 185 & 79 & L1-L2 & 9 & $\mathrm{C}$ & 11 \\
\hline $\mathrm{C} 2$ & $\mathrm{~F}$ & 31 & 161 & 50 & T9-T10 & 17 & $\mathrm{C}$ & 25 \\
\hline $\mathrm{C} 4$ & M & 35 & 173 & 76 & T5 & 1 & $\mathrm{C}$ & 19 \\
\hline $\mathrm{C} 5$ & $\mathrm{~F}$ & 33 & 166 & 63 & $\mathrm{C} 5-\mathrm{T} 1$ & $<1$ & $\mathrm{C}$ & 13 \\
\hline D2 & M & 64 & 168 & 114 & C5-C6 & $<1$ & $\mathrm{D}$ & 50 \\
\hline D3 & $\mathrm{F}$ & 34 & 172 & 60 & $\mathrm{~T} 7$ & 8 & $\mathrm{D}$ & 31 \\
\hline D4 & M & 63 & 180 & 83 & $\mathrm{C} 3$ & 5 & $\mathrm{D}$ & 44 \\
\hline$\overline{\text { Mean } \pm \text { SD }}$ & - & $49 \pm 14$ & $172 \pm 7$ & $77 \pm 17$ & - & - & - & $26 \pm 15$ \\
\hline
\end{tabular}

during the course of an intervention with robot-assisted gait training and additional physical therapy. This pretestposttest trial is used to assess possible effects of this intervention because it is an essential step before setting up a randomized controlled trial [29]. Cardiorespiratory fitness was evaluated using a graded arm crank exercise test performed at baseline and immediately after the training program. To examine the intensity of the training program, we measured $\dot{\mathrm{VO}}_{2}$ and HR during training sessions at the start and end of the training program.

\section{Training Program}

The training program consisted of 24 training sessions with a Lokomat device, with additional physical therapy sessions completed within 10 to 16 weeks. Training sessions were performed two or three times per week with at least $1 \mathrm{~d}$ of rest between two sessions. Each robotic training session lasted $60 \mathrm{~min}$ and contained 20 to 40 min walking time. Subjects trained with an individually adapted walking speed, BWS, and robotic support (guidance force $[\mathrm{GF}]$ ) in such a way that he or she was able to walk comfortably for about $30 \mathrm{~min}$. Training settings were adjusted individually by optimizing BWS, speed, and GF as long as the training settings were tolerated by the subject. The additional physical therapy sessions consisted of usual home-based therapy at a local physical therapy practice or therapy in the rehabilitation center, which focused mainly on walking ability. This additional physical therapy was individually prescribed.

\section{Arm Crank Exercise Test}

Each subject performed a discontinuous progressive graded exercise test on an Angio arm ergometer (Lode BV; Groningen, the Netherlands) to assess cardiorespiratory function. The exercise tests were carried out by an experienced researcher. Subjects were asked to avoid food, caffeine, and alcohol intake $2 \mathrm{~h}$ prior to the exercise tests. Before the exercise test, resting values of $\mathrm{VO}_{2}$ and HR were measured during $5 \mathrm{~min}$ of seated rest. In recorded test data, there were no signs of hyperventilation or signs for abnormal electrocardiogram (ECG). The exercise protocol consisted of a minimum of three blocks of $3 \mathrm{~min}$ of arm pedaling at $60 \mathrm{rpm}$. The increase in work load was individually set by the researcher such that subjects needed a minimum of three exercise blocks to reach their peak performance. The estimation was based on the exercise performance (HR) of the first exercise block. Rest after each block (1 min) was included to facilitate the measurements for an additional study (recordings of the ECG and impedance cardiogram, see Meijer et al. [30]). Subjects were verbally encouraged to exercise to exhaustion. The exercise test ended when a subject was not able to continue pedaling at $60 \mathrm{rpm}$ because of exhaustion or when the subject indicated that he or she wanted to stop. During the whole exercise test, $\dot{\mathrm{VO}}_{2}$ was continuously monitored with a spirometer (Oxycon Alpha or Oxycon Mobile, Jaeger; Bunnik, the Netherlands). $\dot{\mathrm{V}} \mathrm{O}_{2}$ was measured breath-by-breath and averaged over $5 \mathrm{~s}$ intervals. Pre- and posttest were executed following the same procedure. Figure 1 depicts an example of the experimental setup of the exercise test. 


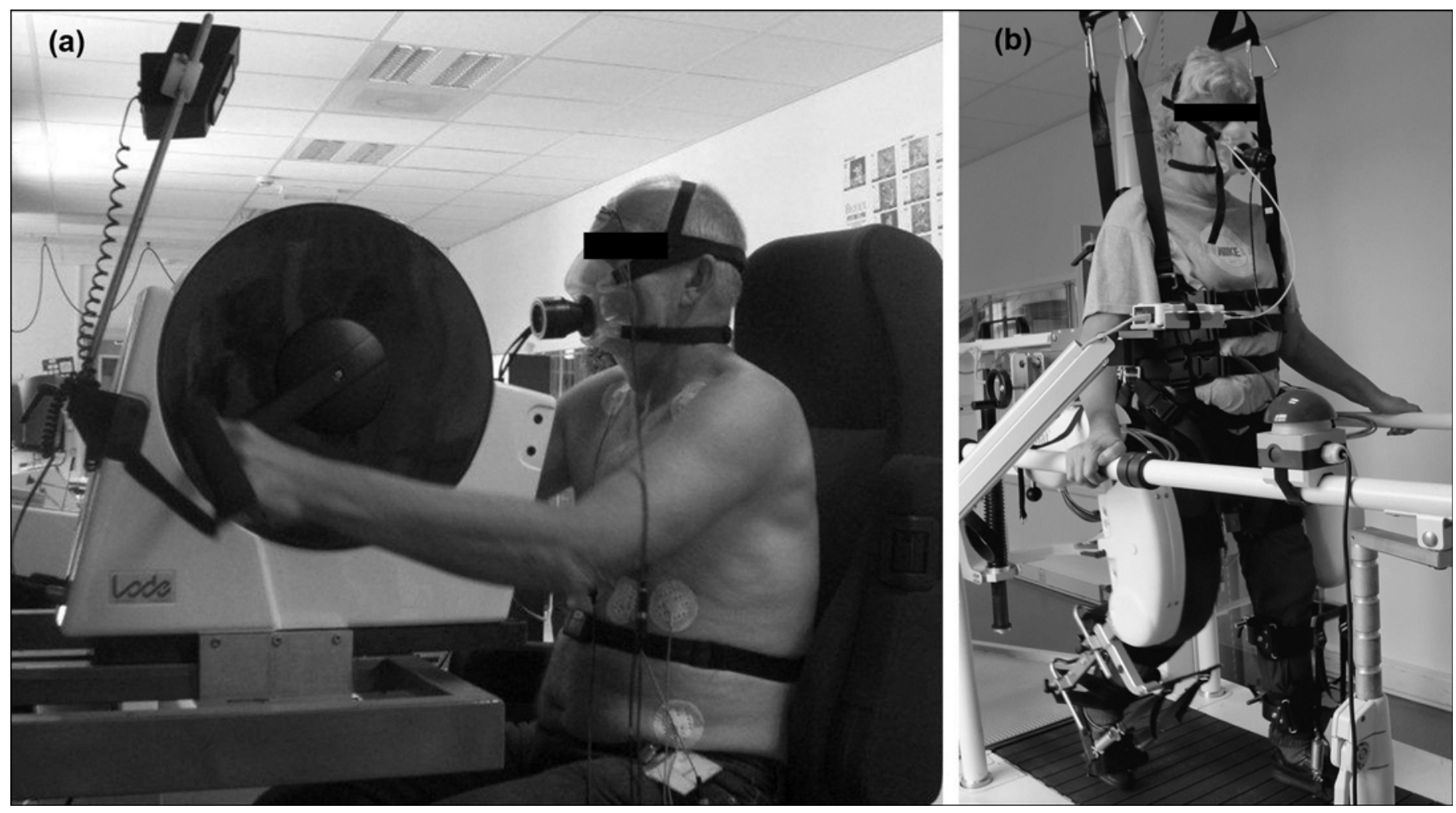

Figure 1.

Experimental setup of (a) arm crank exercise test and (b) tested training sessions.

\section{Robotic Walking Test}

The first measurement was performed during one of the early training sessions (session 6,7 , or 8 ) when subjects had become accustomed to walking in the device. The last measurement was performed during training session 23 or 24 . The timing of assessment was predominantly based on practical reasons (e.g., availability of subjects and measuring equipment). During both measurements, $\dot{\mathrm{VO}}_{2}$ was measured in the same way as during the arm crank exercise test. HR was monitored by a Polar sport tester (Polar RS400/Polar RS800 and Polar WearLink belt, Polar Electro Inc; Lake Success, New York) with a $5 \mathrm{~s}$ recording rate. Prior to the training sessions, resting values of $\dot{\mathrm{VO}}_{2}$ and $\mathrm{HR}$ were measured during 5 min of rest in a sitting position. Figure 1 depicts the experimental setup. The procedure of both tested training sessions was as follows:

1. Subjects performed a 5 to $10 \mathrm{~min}$ warm up to familiarize themselves with the equipment and to warm up their legs.

2. Part 1: Walking at an individually standardized walking condition. During the first part of the training ses- sion, individually adapted walking speed, BWS, and GF were kept constant for at least 4 min to obtain steady-state values of $\dot{\mathrm{VO}}_{2}$ and HR. During both tested training sessions, the individually standardized walking settings of the robotic support were identical for each subject.

3. Part 2: Exercise intensity of robotic walking. During the last part of the training session, walking speed, BWS, and GF were adjusted in such a way, representative of a regular training session at that moment, to measure the exercise intensity.

\section{Outcome Measures of Cardiorespiratory Fitness}

Eight outcome measures were used from the graded arm crank test. Resting $\dot{\mathrm{VO}}_{2}$ and $\mathrm{O}_{2}$ pulse were determined as the average over the last $60 \mathrm{~s}$ of quiet sitting. Submaximal $\dot{\mathrm{VO}}_{2}$ and $\mathrm{O}_{2}$ pulse were determined as the average of the last $30 \mathrm{~s}$ of block 2 of the arm crank exercise test. During block 2, subjects exercised at a submaximal intensity with a constant work load. Peak $\dot{\mathrm{VO}}_{2}$ was determined as the average of the last $20 \mathrm{~s}$ of the last block of the arm crank exercise test. Furthermore, the lowest 
obtained HR during the last minute of seated rest was used as resting HR; submaximal HR was determined as the average of the last $30 \mathrm{~s}$ of block 2, and peak HR was the highest HR found in the last block (block 3). The recorded ECG was used to determine the resting, submaximal, and peak HR and resting and submaximal $\mathrm{O}_{2}$ pulse. $\mathrm{O}_{2}$ pulse as a measure for cardiovascular efficiency was determined according to the following (Equation (1)):

$$
\mathrm{O}_{2} \text { pulse }(\mathrm{mL} / \text { beat })=\frac{\text { Oxygen consumption }(\mathrm{mL} / \mathrm{min})}{\text { Heart rate }(\mathrm{bpm})} \text {. }
$$

A higher submaximal $\mathrm{O}_{2}$ pulse after the training program would therefore indicate an improvement in cardiovascular efficiency. Changes in submaximal $\dot{\mathrm{V}}_{2}$ at a given workload would reflect changes in mechanical efficiency (e.g., due to better coordination of arm muscles).

\section{Outcome Measures of Robotic Walking Intensity}

Nine outcome measures from the robotic walking trials were used for analysis. Resting $\mathrm{V}_{2 \text { robot }}$ was determined as the average of the last $60 \mathrm{~s}$ during seated rest. Resting $\mathrm{HR}_{\text {robot }}$ was determined as the lowest obtained HR during sitting. Furthermore, the average of values over $10 \mathrm{~min}$ of robotic walking during the last part of the training session were determined ( $\left(\mathrm{V}_{2 \text { robot }}\right.$ and $\left.\mathrm{HR}_{\text {robot }}\right)$. Finally, steady-state values of $\dot{\mathrm{VO}}_{2}$ and $\mathrm{HR}$, measured during the standardized robotic walking task, were calculated by averaging the last $60 \mathrm{~s}$ of walking at the specific standardized walking condition. $\dot{\mathrm{V}} \mathrm{O}_{2 \text { robot }}$ measures were expressed as a percentage of $\dot{\mathrm{V}} \mathrm{O}_{2}$ reserve $\left(\% \dot{\mathrm{VO}}_{2} \mathrm{R}\right)$ [31] and metabolic equivalents (METs) [31], and $\mathrm{HR}_{\text {robot }}$ was expressed as a percentage of HR reserve (\%HRR) [31]. The $\% \mathrm{HRR}, \% \mathrm{VO}_{2} \mathrm{R}$, and METs were used as measures for the exercise intensity of the training program and were calculated using the following (Equations (2)-(4)):

$$
\begin{gathered}
\% \mathrm{HRR}=\frac{\mathrm{HR}_{\text {robot }}-\mathrm{HR}_{\text {rest }}}{\mathrm{HR}_{\text {peak }}-\mathrm{HR}_{\text {rest }}} \times 100 . \\
\% \dot{\mathrm{VO}}_{2 \mathrm{R}}=\frac{\dot{\mathrm{VO}}{ }_{2 \text { robot }}-\dot{\mathrm{V}} \mathrm{O}_{2 \text { rest }}}{\dot{\mathrm{V}} \mathrm{O}_{2 \text { peak }}-\dot{\mathrm{VO}} \mathrm{O}_{2 \text { rest }}} \times 100 . \\
\mathrm{METs}=\frac{\dot{\mathrm{VO}}{ }_{2 \text { robot }}}{\dot{\mathrm{V} O} \mathrm{O}_{2 \text { rest }}}
\end{gathered}
$$

Subsequently, the obtained $\% \mathrm{HRR}, \% \dot{\mathrm{VO}}{ }_{2} \mathrm{R}$, and METs were compared with exercise intensity recommendations for sedentary people [31]. ACSM guidelines for sedentary and/or extremely deconditioned nondisabled adults recommend training at an intensity of 30 to $45 \% \mathrm{HRR}$ or $\% \mathrm{VO}_{2} \mathrm{R}$ in order to maintain or improve physical fitness.

\section{Statistical Analysis}

After checking whether the data followed a normal distribution, paired $t$-tests were used to determine whether there were significant differences in resting, submaximal, and peak $\dot{\mathrm{VO}}_{2}, \mathrm{HR}$, and $\mathrm{O}_{2}$ pulse between preand posttest arm crank tests or between both tested training sessions. Mean \pm standard deviation was computed (but not all reported) for all outcome measures (Tables 2-3). Furthermore, the mean differences (with 95\% confidence interval) were also calculated. All statistical analyses were performed using SPSS version 19.0 for Windows (IBM Corporation; Armonk, New York). The significance level was set at 5 percent.

\section{RESULTS}

\section{Arm Crank Exercise Test}

One subject was unable to perform the arm crank exercise test due to inability to pedal with the device. Figure 2 depicts the individual values of resting $\mathrm{HR}$ and $\mathrm{O}_{2}$ pulse; submaximal $\mathrm{HR}, \mathrm{O}_{2}$ pulse, and $\dot{\mathrm{V}} \mathrm{O}_{2}$; and peak $\dot{\mathrm{V}} \mathrm{O}_{2}$. Table 2 shows the resting, submaximal, and peak values of $\mathrm{V}_{2}$ (absolute and normalized for body mass), $\mathrm{HR}$, and $\mathrm{O}_{2}$ pulse measured during both tests. As expected, the $t$-test showed no significant difference in submaximal $\dot{\mathrm{V}}_{2}$ between pre- and posttest, but submaximal HR was significantly lower after the training program (Table 2, Figure 2). As a result of a lower submaximal $\mathrm{HR}$ at the similar submaximal $\mathrm{VO}_{2}$, submaximal $\mathrm{O}_{2}$ pulse tended to be higher during the posttest. In line with submaximal values, resting HR was significantly lower at posttest than at pretest.

\section{Robotic Walking Test}

No changes were found in $\dot{\mathrm{V}} \mathrm{O}_{2 \text { robot }}$ and $\mathrm{HR}_{\text {robot }}$ between the first and last tested training sessions (Table 3). Although not significant $(p<0.1)$, almost all subjects had lower steady-state $\dot{\mathrm{VO}}_{2}$ and HR during the standardized robotic walking task at the last training session compared 
Table 2.

Mean \pm standard deviation (SD) of resting, submaximal, and peak oxygen consumption $\left(\dot{\mathrm{VO}}_{2}\right)$, heart rate $(\mathrm{HR})$, and $\mathrm{O}_{2}$ pulse measured during both arm crank exercise tests (pre- and posttest) $(n=9)$.

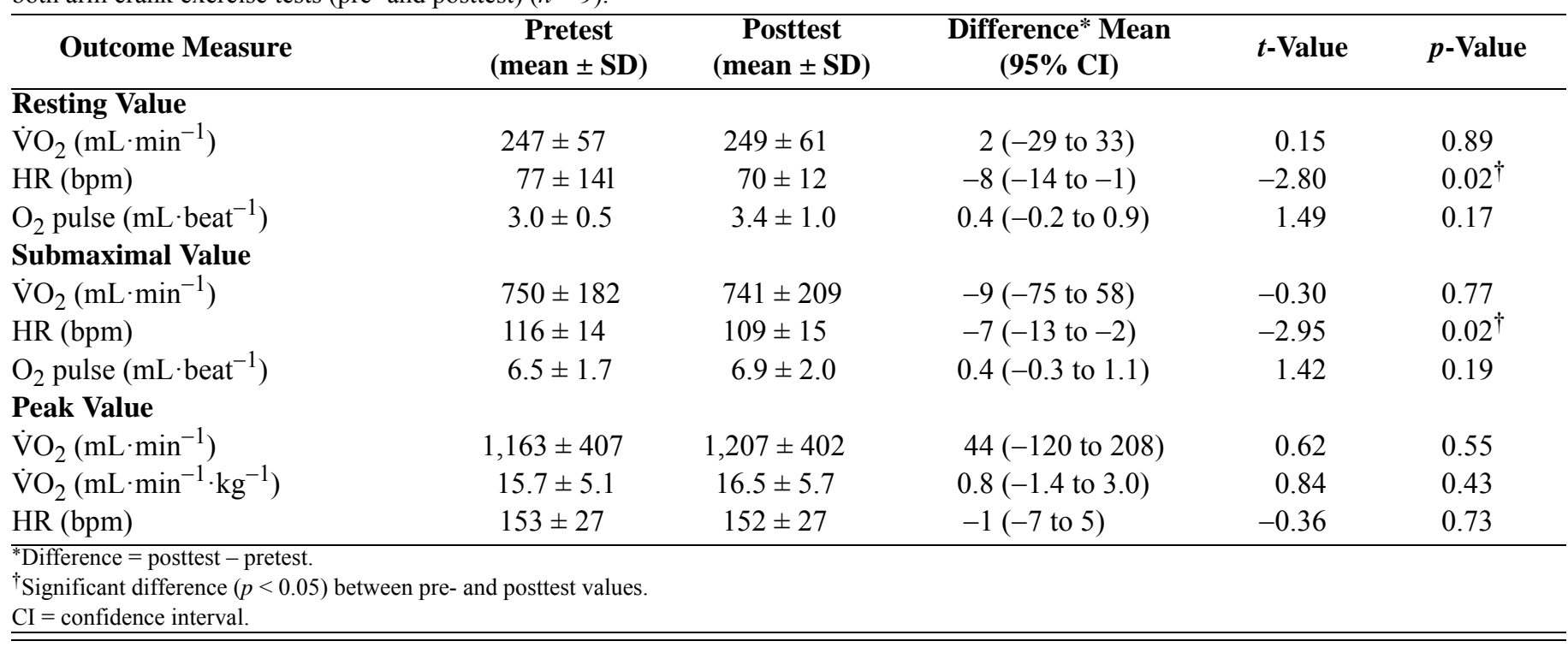

Table 3.

Mean \pm standard deviation (SD) values of oxygen consumption $\left(\mathrm{V}_{2}\right)$ and heart rate $(\mathrm{HR})$ together with exercise intensity measures determined during training session at start (first training) and end (last training) of training program.

\begin{tabular}{|c|c|c|c|c|c|c|}
\hline Measure & $n$ & $\begin{array}{l}\text { First Training } \\
\text { (mean } \pm \text { SD) }\end{array}$ & $\begin{array}{c}\text { Last Training } \\
(\text { mean } \pm \text { SD) }\end{array}$ & $\begin{array}{c}\text { Difference* }^{*} \text { Mean } \\
(95 \% \mathrm{CI})\end{array}$ & t-Value & $p$-Value \\
\hline \multicolumn{7}{|l|}{ Robotic Walking } \\
\hline$\dot{\mathrm{V}} \mathrm{O}_{2 \text { robot }}\left(\mathrm{mL} \cdot \mathrm{min}^{-1}\right)$ & 10 & $536 \pm 226$ & $492 \pm 203$ & $-44(-109$ to 21$)$ & -1.54 & 0.16 \\
\hline $\mathrm{HR}_{\text {robot }}(\mathrm{bpm})$ & 10 & $94 \pm 13$ & $88 \pm 10$ & $-6(-13$ to 2$)$ & -1.73 & 0.12 \\
\hline Steady-state $\mathrm{VO}_{2}\left(\mathrm{~mL} \cdot \mathrm{min}^{-1}\right)$ & 10 & $558 \pm 267$ & $453 \pm 184$ & $-105(-215$ to 4$)$ & -2.17 & 0.06 \\
\hline$\% \dot{\mathrm{V}}{ }_{2} \mathrm{R}$ & 8 & $23 \pm 14$ & $20 \pm 13$ & $3(-9$ to 3$)$ & -1.01 & 0.35 \\
\hline$\% \mathrm{HRR}$ & 7 & $23 \pm 10$ & $14 \pm 11$ & $-8(-16$ to -0.3$)$ & -2.56 & $0.04^{\dagger}$ \\
\hline MET & 10 & $2.2 \pm 0.9$ & $2.1 \pm 0.9$ & $-0.1(-0.4$ to 0.1$)$ & -1.37 & 0.21 \\
\hline
\end{tabular}

with the first tested training session. Two subjects (D2 and D4) obtained their peak $\mathrm{VO}_{2}$ and HR during robotic walking instead of the arm crank exercise test. Therefore, it was not possible to calculate valid values for $\% \mathrm{HRR}$ and $\% \dot{\mathrm{V}} \mathrm{O}_{2} \mathrm{R}$ of robotic walking for these subjects. Also, the $\% \mathrm{HRR}$ of the last tested training session of subject D1 was excluded from the analyses, because during the whole training session, the HRs of subject D1 were substantially higher than all other tests, resulting in a much higher \%HRR. For the remaining individuals, no signifi- cant differences in $\% \dot{\mathrm{V}} \mathrm{O}_{2} \mathrm{R}$ and METs were found between the start and end of the training program (Table 3). However, \%HRR was significantly lower at the last training session than the first tested session.

Figure 3 presents individual results of $\% \dot{\mathrm{VO}}_{2} \mathrm{R}$, $\% \mathrm{HRR}$, and METs obtained at both tested training sessions. Based on the $\% \dot{\mathrm{V}} \mathrm{O}_{2} \mathrm{R}$ measured at the first tested training session, only subjects $\mathrm{C} 3, \mathrm{C} 4$, and $\mathrm{D} 1$ met the recommended guidelines of exercise intensity. During the last training session, subjects C3, D1, and D3 achieved 
(a)

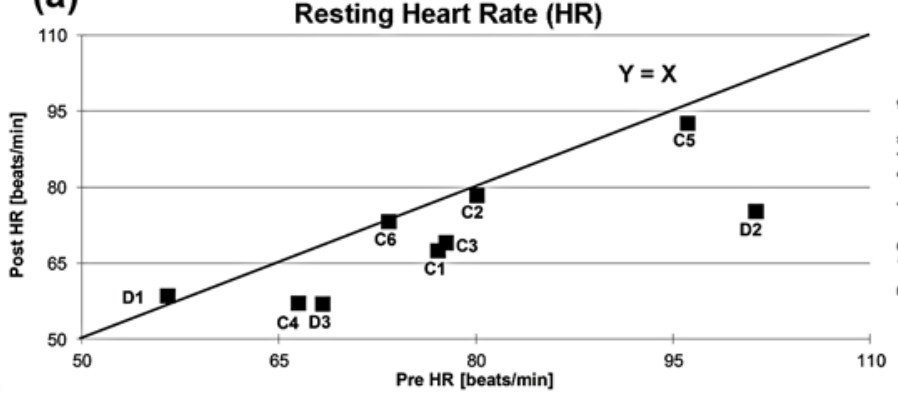

(c)

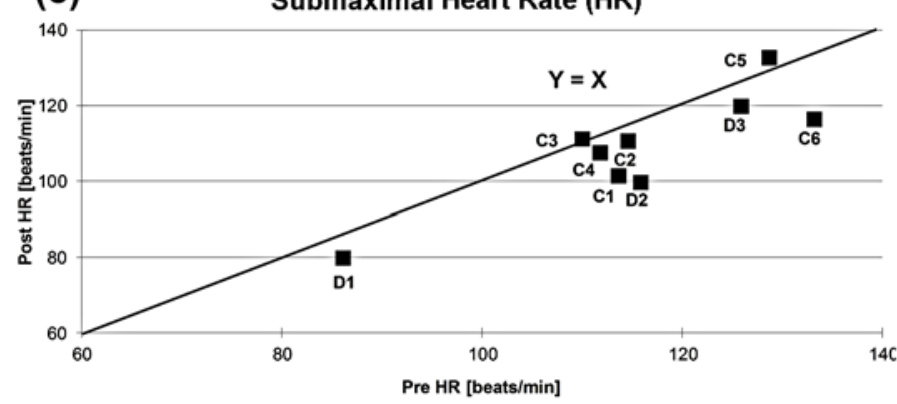

(e)

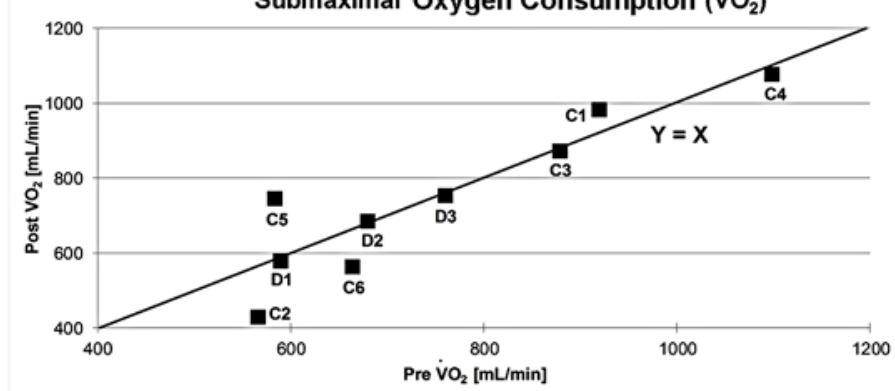

(b) Resting Oxygen Pulse $\left(\mathrm{O}_{2}\right.$ pulse $)$

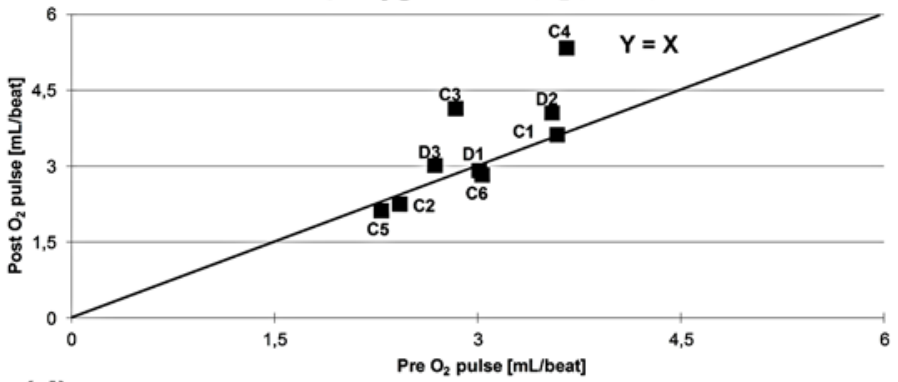

(d)

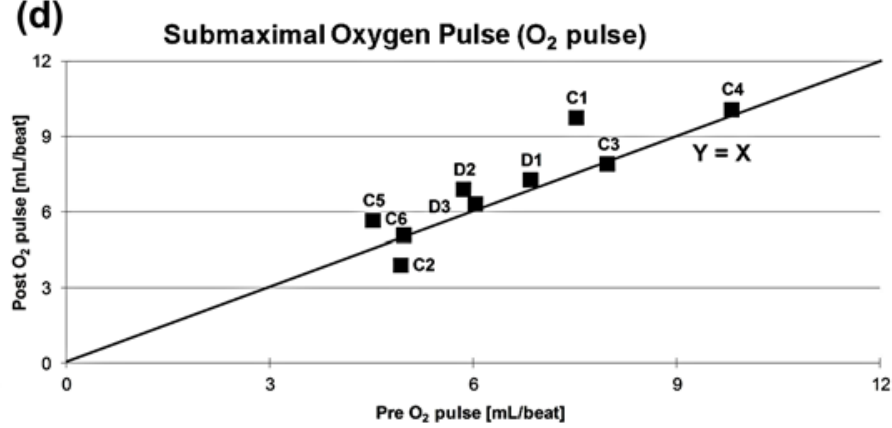

(f)

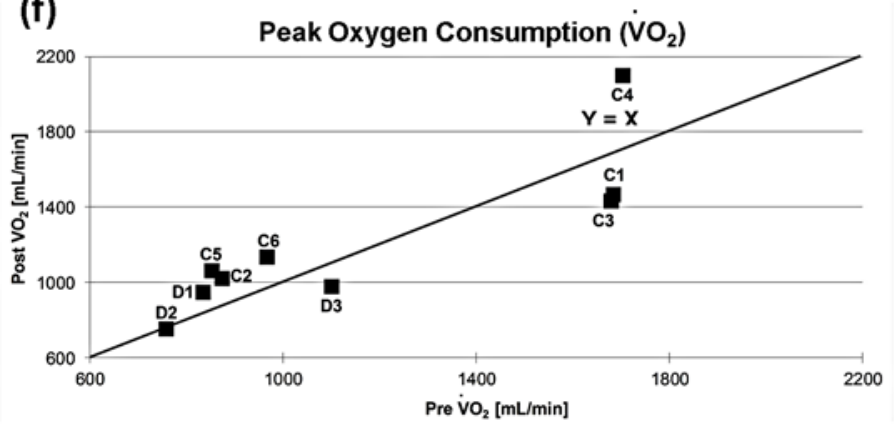

Figure 2.

Individual values of (a) resting heart rate (HR), (b) resting $\mathrm{O}_{2}$ pulse, (c) submaximal $\mathrm{HR}$, (d) submaximal $\mathrm{O}_{2}$ pulse, (e) submaximal oxygen consumption $\left(\mathrm{V}_{2}\right)$, and (f) peak $\dot{\mathrm{V}}_{2}$ measured during both arm crank exercise tests (pre- and posttest). Line of identity $(y=$ $x$ ), which illustrates no change between pre- and posttest, is also shown in graphs. Resting and submaximal HR at posttest were significantly lower than at pretest. No significant changes were found in resting $\mathrm{O}_{2}$ pulse, submaximal $\mathrm{O}_{2}$ pulse, submaximal $\dot{\mathrm{V}} \mathrm{O}_{2}$, and peak $\mathrm{V}_{2}$. AIS = American Spinal Injury Association Impairment Scale, $\mathrm{C}=$ participant with AIS level C, D = participant with AIS level D.

a $\% \dot{\mathrm{V}} \mathrm{O}_{2} \mathrm{R}$ above the minimum recommended value of $30 \% \mathrm{VO}_{2} \mathrm{R}$. In the same way, it is illustrated that at the start of the training program, the \%HRR of subjects $\mathrm{C} 3$, $\mathrm{C} 6$, and D1 was above the recommended guidelines. At the end of the training program, only subject $\mathrm{C} 3$ exercised at an intensity above $30 \% \mathrm{HRR}$. $\dot{\mathrm{VO}}_{2}$ during robotic walking was one to three times higher than $\mathrm{VO}_{2}$ at rest in most subjects. Only subjects C3 and D4 achieved a MET value above 3.0, which is considered exercising at moderate intensity. $\dot{\mathrm{VO}}_{2}$ during robotic walking of subject $\mathrm{C} 5$ was nearly the same as her resting $\dot{\mathrm{VO}}_{2}$.

\section{DISCUSSION}

In this study, exercise intensity of walking in the Lokomat was investigated in subjects with iSCI. Results indicated that the exercise intensity in these subjects was predominantly below recommended levels for sedentary persons on both assessments during the study. Based on the submaximal $\dot{\mathrm{VO}}_{2}$ and $\mathrm{HR}$ values during the arm crank test, this study shows that cardiorespiratory fitness might have increased during the intervention. The fact that there was no change in peak $\dot{\mathrm{VO}}_{2}$ of the arm exercise test does 
(a) Excercise Intensity (\%نंO ${ }_{2}$ Reserve) of Robotic Walking

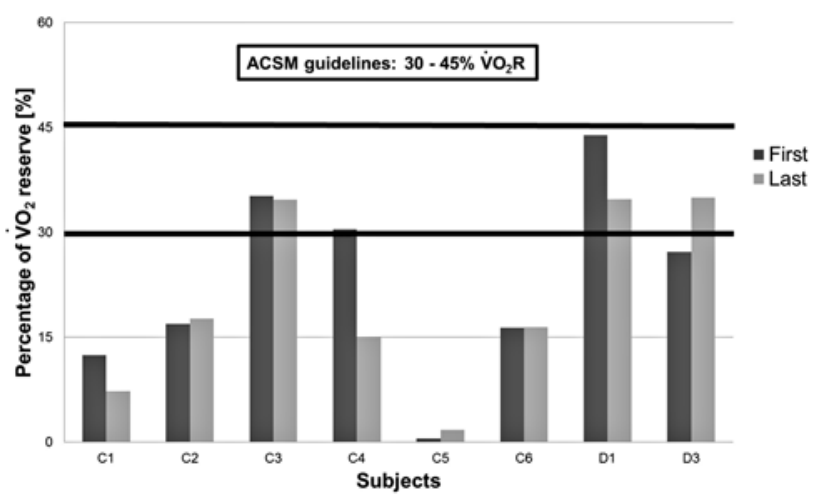

(b)

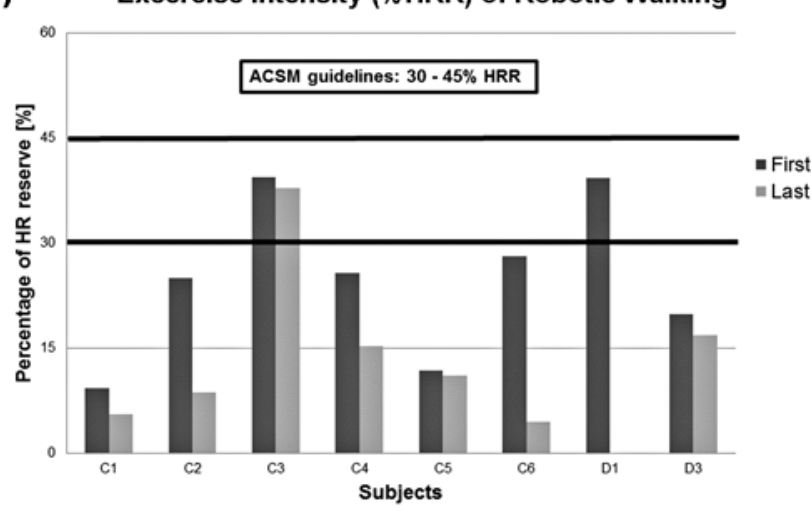

(c)

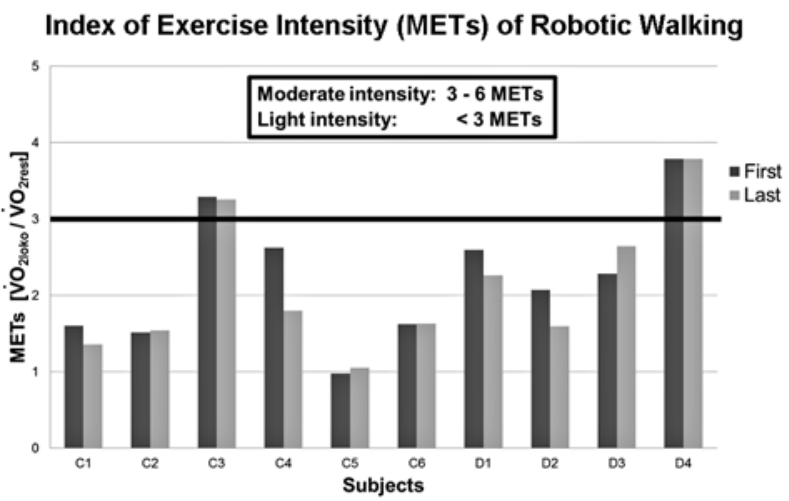

Figure 3.

Individual values of (a) percentage of oxygen consumption reserve $\left(\% \mathrm{VO}_{2} \mathrm{R}\right)$, (b) percentage of heart rate reserve (\%HRR), and (c) metabolic equivalents (METs) of robotic walking during both tested training sessions. Black lines indicate recommended exercise intensity according to American College of Sports Medicine (ACSM) guidelines [31]. Most subjects exercised below this minimum level of exercise intensity. not necessarily suggest that cardiorespiratory fitness did not improve after the training program. Peak $\mathrm{V}_{2}$ determined during an arm exercise test is mainly limited by local factors (small muscle mass) rather than central factors (lungs or heart) [32-34]. Since the intervention was aimed at the legs, the exercise capacity of the arm muscle was assumed to be unchanged. Because of peripheral limitations, it is conceivable that the peak $\mathrm{VO}_{2}$ as measured during an arm crank test did not change, while a subject's actual aerobic fitness did improve. By considering this limitation, we valued the submaximal values as more informative of whether cardiorespiratory fitness had improved. We used the arm crank test instead of a test using the lower limbs because we wanted to rule out the effect of possible improvements in neurological impairments in the legs elicited by the intervention. Such improvements would have the effect of increased muscle mass being employed during the exercise test, which could lead to a higher $\dot{\mathrm{VO}}_{2}$ that was not due to improvements in cardiorespiratory fitness. It appeared that after the robot-assisted gait training, subjects had a significantly lower submaximal HR during arm crank exercise at the same work load and $\dot{\mathrm{VO}}_{2}$. Although this suggests improved cardiovascular efficiency, we did not find a significantly lower $\mathrm{O}_{2}$ pulse, suggesting that the improvements are rather small. Furthermore, subjects had a significantly lower resting HR after a period of robotassisted gait training, again suggesting improved cardiorespiratory fitness. Although these results should be interpreted with caution, together these results indicate small improvements in cardiorespiratory fitness.

The small improvements in cardiorespiratory fitness is rather surprising in light of the exercise intensity of the training program. The ACSM guidelines for exercise prescription [31] and Ginis et al. [35] recommend that people with SCI should participate in an aerobic exercise activity of moderate to vigorous exercise intensity $(30-60 \% \mathrm{HRR}$, $30-60 \% \dot{\mathrm{VO}}_{2} \mathrm{R}$, or $\left.3.0-6.0 \mathrm{METs}\right)$ at least twice per week. The majority of the subjects, however, did not reach this minimum level and exercised at very low intensity $\left(<20 \% \dot{\mathrm{VO}}{ }_{2} \mathrm{R}\right.$ or $\left.<20 \% \mathrm{HRR}\right)$. In line with findings of the present study, van den Berg et al. found that a low-intensity training program $(30 \% \mathrm{HRR})$ can improve physical capacity in untrained, nondisabled subjects [36]. Especially for sedentary people, low exercise intensity seems to be safer and is associated with a higher motivation [37]. In this light, robotic walking may be an attractive lowintensity exercise mode for people with iSCI. 
Furthermore, the results showed that almost all subjects achieved lower submaximal $\dot{\mathrm{VO}}_{2}$ and HR by performing the same robotic walking task after the training period, suggesting an improved ability to employ the assistance of the device or an improvement in "robotic walking economy" [38]. This improved ability to employ the assistance of the device or improvement in robotic walking economy might explain that most subjects had a lower \%HRR at the end of the training program than at the start. Furthermore, the average value of $\% \dot{\mathrm{VO}}_{2} \mathrm{R}$ was lower at the last training session, suggesting that subjects adapted to the training program. Although during every training session subjects were encouraged to contribute actively to the robotic walking activity, it was not always possible to reduce the robotic support in a way desirable because of spasticity, risk of wounds, and/or muscle weakness. This improved ability to employ the assistance of the device or improved walking economy was also observed in a study of the longitudinal changes in cardiopulmonary function during an intervention with robotassisted gait training in two subjects with iSCI [38]. Nevertheless, contrary to our results, cardiorespiratory fitness did not improve in that study. Jack et al. suggested that the improvement in robotic walking economy was mainly the result of a better gait pattern instead of changes in cardiopulmonary system [38].

The average level of exercise intensity of robotic walking found in this study (2.2 METs) was higher than found for passive walking in Jack et al. (1.4 METs) [24] but lower than for active walking in studies of Israel et al. [23] and Hunt et al. [39] (2.5 and 4.0 METs, respectively). Israel et al. [23], Hunt et al. [39], and Jack et al. [40] also presented values for peak $\mathrm{VO}_{2}(14,16$, and $28 \mathrm{~mL} / \mathrm{kg} / \mathrm{min}$, respectively) obtained during maximal active robotic walking that were substantially higher than values of the present study $\left(\dot{\mathrm{VO}}_{2 \text { robot }}=6.8 \mathrm{~mL} / \mathrm{kg} / \mathrm{min}\right)$. During active walking in these studies, subjects were supposed to push against the orthoses with their legs while walking. When walking with less GF applied to the legs, such instruction would probably lead to emergency stops of the device since safety limits will be surpassed. Another explanation for the difference in exercise intensity between our study and the literature is the level of impairment, given that the legs can be loaded more when less impaired. Relatively more individuals with AIS level D participated in the studies by Israel et al. [23], Hunt et al. [39], and Jack et al. [40] than in our study. It is likely that the greater impairment of subjects in the present study has at least in part contributed to the lower exercise intensities found. Nevertheless, when subjects are encouraged to push against the orthoses of the Lokomat device during walking, as was done in Jack et al. [40], it seems conceivable that exercise intensity can increase.

Limitations of this study are the small sample size and heterogeneity of the study population, the latter resulting in interindividual differences in the level of physical capacity and the differences of exercise intensity of the intervention. Furthermore, the $\% \dot{\mathrm{V}} \mathrm{O}_{2} \mathrm{R}$ and $\% \mathrm{HRR}$ were calculated using the resting and peak values of $\dot{\mathrm{V}} \mathrm{O}_{2}$ and HR. Resting $\dot{\mathrm{VO}}_{2}$ was determined after 5 min of quiet sitting, which although commonly used, might not be optimal when assessing resting values [41]. This might have resulted in overestimation of the resting values of $\dot{\mathrm{VO}}_{2}$ and $\mathrm{HR}$, which in turn, results in underestimation of $\% \dot{\mathrm{VO}}{ }_{2} \mathrm{R}$ and \%HRR. On the other hand, the possibility exists that peak values of $\mathrm{VO}_{2}$ and $\mathrm{HR}$ were underestimated because of different factors such as subject motivation, day-to-day variations, the exercise protocol, and exercise modality. For this reason, the \%HRR of the last assessment of subject D1 was excluded from the analyses. Furthermore, it was not possible to calculate valid values of $\% \mathrm{VO}_{2} \mathrm{R}$ and $\% \mathrm{HRR}$ in two subjects (D2 and D4), because they obtained their peak $\dot{\mathrm{VO}}_{2}$ and HR during robotic walking instead of during the arm crank exercise test. An alternative would be that peak HR would be estimated based on age. However, this could result in overestimation of the maximal HR since individuals with SCI above thoracic level 4 may have impaired sympathetic innervations of the heart. Therefore, we chose the method presented in this article. To complement the results of the $\% \mathrm{VO}_{2} \mathrm{R}$ and $\% \mathrm{HRR}$, we also calculated MET values. By comparing the $\dot{\mathrm{V}} \mathrm{O}_{2}$ and $\mathrm{HR}$ of both standardized robotic walking tasks, the assumption was made that external load was kept the same in both conditions. However, in this study, the amount of handrail support, which can influence the external load, was not completely standardized during both tests. Ideally, handrail support should be avoided during the testing period. However, some subjects were not able to walk without handrail support. Despite this possible variation in external load, almost all subjects had a lower $\dot{\mathrm{VO}}_{2}$ and $\mathrm{HR}$ at the last measurement compared with the first, which still indicates an improvement in robotic walking economy. 


\section{CONCLUSIONS}

The majority of the subjects exercised below the minimum level of the recommended exercise intensity $\left(<30 \% \dot{\mathrm{V} O}{ }_{2} \mathrm{R},<30 \% \mathrm{HRR}\right.$, and $\left.<3.0 \mathrm{METs}\right)$. In spite of the low exercise intensity of the training program and no changes in peak $\dot{\mathrm{VO}}_{2}$ of the arm exercise test, the lower resting and submaximal HR suggest that a period of robotassisted gait training may have induced some improvement in cardiorespiratory fitness. Furthermore, almost all subjects had lower $\dot{\mathrm{VO}}_{2}$ and HR during the same robotic walking task after the training period, reflecting a higher robotic walking economy. Therefore, treadmill walking, including robot-assisted walking, might not only help in improving walking ability but also have secondary effects such as improvement in cardiorespiratory fitness, as found in this study. Whether these effects are different from conventional therapy approaches may be studied in future randomized clinical trials.

\section{ACKNOWLEDGMENTS}

\section{Author Contributions:}

Study concept and design: F. Hoekstra, M. P. M. van Nunen,

K. H. L. Gerrits, T. W. J. Janssen.

Acquisition of data: F. Hoekstra, M. H. P. Crins.

Analysis and interpretation of data: F. Hoekstra, M. P. M. van Nunen,

J. M. Stolwijk-Swüste, T. W. J. Janssen.

Drafting of manuscript: F. Hoekstra.

Critical revision of manuscript for important intellectual content:

F. Hoekstra, M. P. M. van Nunen, K. H. L. Gerrits, J. M. Stolwijk-

Swüste, M. H. P. Crins, T. W. J. Janssen.

Statistical analysis: F. Hoekstra.

Obtained funding: K. H. L. Gerrits, T. W. J. Janssen.

Administrative, technical, or material support: F. Hoekstra,

M. P. M. van Nunen.

Study supervision: M. P. M. van Nunen, K. H. L. Gerrits, T. W. J. Janssen.

Financial Disclosures: The authors have declared that no competing interests exist.

Funding/Support: This material was based on work supported by the Dutch Heart Foundation (Hartstichting, grant 07.21) and Revalidatiefonds (project 2007166). The study was conducted at Reade Amsterdam Rehabilitation Research Center, Amsterdam, the Netherlands.

Additional Contributions: We thank Thijs Schoots for the assistance with data acquisition. Dr. Stolwijk-Swütse is now with the Department of Rehabilitation, Meander Medical Center, Amersfoort, the Netherlands.

Institutional Review: The study protocol was approved by the ethics committee of the VU University Medical Center Amsterdam. All participants provided written informed consent before enrolling in the study.
Participant Follow-Up: The participants will be informed of the publication of this study.

\section{REFERENCES}

1. Buchholz AC, Pencharz PB. Energy expenditure in chronic spinal cord injury. Curr Opin Clin Nutr Metab Care. 2004;7(6):635-39. [PMID:15534431]

http://dx.doi.org/10.1097/00075197-200411000-00008

2. Slentz CA, Houmard JA, Kraus WE. Exercise, abdominal obesity, skeletal muscle, and metabolic risk: Evidence for a dose response. Obesity (Silver Spring). 2009;17(Suppl 3): S27-33. [PMID:19927142]

http://dx.doi.org/10.1038/oby.2009.385

3. Thijssen DH, Maiorana AJ, O'Driscoll G, Cable NT, Hopman MT, Green DJ. Impact of inactivity and exercise on the vasculature in humans. Eur J Appl Physiol. 2010; 108(5):845-75. [PMID:19943061] http://dx.doi.org/10.1007/s00421-009-1260-x

4. Haennel RG, Lemire F. Physical activity to prevent cardiovascular disease. How much is enough? Can Fam Physician. 2002;48:65-71. [PMID:11852614]

5. Haskell WL, Lee IM, Pate RR, Powell KE, Blair SN, Franklin BA, Macera CA, Heath GW, Thompson PD, Bauman A. Physical activity and public health: Updated recommendation for adults from the American College of Sports Medicine and the American Heart Association. Med Sci Sports Exerc. 2007;39(8):1423-34. [PMID:17762377] http://dx.doi.org/10.1249/mss.0b013e3180616b27

6. Sofi F, Capalbo A, Cesari F, Abbate R, Gensini GF. Physical activity during leisure time and primary prevention of coronary heart disease: An updated meta-analysis of cohort studies. Eur J Cardiovasc Prev Rehabil. 2008;15(3):247-57. [PMID:18525378] http://dx.doi.org/10.1097/HJR.0b013e3282f232ac

7. Alm M, Saraste H, Norrbrink C. Shoulder pain in persons with thoracic spinal cord injury: Prevalence and characteristics. J Rehabil Med. 2008;40(4):277-83. [PMID:18382823

8. Dyson-Hudson TA, Kirshblum SC. Shoulder pain in chronic spinal cord injury, Part I: Epidemiology, etiology, and pathomechanics. J Spinal Cord Med. 2004;27(1):4-17. [PMID:15156931]

9. Jain NB, Higgins LD, Katz JN, Garshick E. Association of shoulder pain with the use of mobility devices in persons with chronic spinal cord injury. PM R. 2010;2(10):896900. [PMID:20970758] http://dx.doi.org/10.1016/j.pmrj.2010.05.004

10. Davis GM, Hamzaid NA, Fornusek C. Cardiorespiratory, metabolic, and biomechanical responses during functional electrical stimulation leg exercise: Health and fitness benefits. 
Artif Organs. 2008;32(8):625-29. [PMID:18782133]

http://dx.doi.org/10.1111/j.1525-1594.2008.00622.x

11. Hettinga DM, Andrews BJ. Oxygen consumption during functional electrical stimulation-assisted exercise in persons with spinal cord injury: Implications for fitness and health. Sports Med. 2008;38(10):825-38.

[PMID:18803435]

http://dx.doi.org/10.2165/00007256-200838100-00003

12. van Asbeck FW, Post MW, Pangalila RF. An epidemiological description of spinal cord injuries in The Netherlands in 1994. Spinal Cord. 2000;38(7):420-24.

[PMID:10962602]

http://dx.doi.org/10.1038/sj.sc.3101003

13. Hicks AL, Ginis KA. Treadmill training after spinal cord injury: It's not just about the walking. J Rehabil Res Dev. 2008;45(2):241-48. [PMID:18566942] http://dx.doi.org/10.1682/JRRD.2007.02.0022

14. Colombo G, Joerg M, Schreier R, Dietz V. Treadmill training of paraplegic patients using a robotic orthosis. J Rehabil Res Dev. 2000;37(6):693-700. [PMID:11321005]

15. Colombo G, Wirz M, Dietz V. Driven gait orthosis for improvement of locomotor training in paraplegic patients. Spinal Cord. 2001;39(5):252-55. [PMID:11438840] http://dx.doi.org/10.1038/sj.sc.3101154

16. Alcobendas-Maestro M, Esclarín-Ruz A, Casado-López RM, Muñoz-González A, Pérez-Mateos G, GonzálezValdizán E, Martín JL. Lokomat robotic-assisted versus overground training within 3 to 6 months of incomplete spinal cord lesion: Randomized controlled trial. Neurorehabil Neural Repair. 2012;26(9):1058-63.

[PMID:22699827]

http://dx.doi.org/10.1177/1545968312448232

17. Hornby GT, Campbell DD, Zemon DH, Kahn JH. Clinical and quantitative evaluation of robotic-assisted treadmill walking to retrain ambulation after spinal cord injury. Top Spinal Cord Inj Rehabil. 2005;11(2):1-17. http://dx.doi.org/10.1310/14Q9-AD7M-FXX9-1G2J

18. Ditor DS, Kamath MV, MacDonald MJ, Bugaresti J, McCartney N, Hicks AL. Effects of body weight-supported treadmill training on heart rate variability and blood pressure variability in individuals with spinal cord injury. J Appl Physiol. 2005;98(4):1519-25. [PMID:15563629] http://dx.doi.org/10.1152/japplphysiol.01004.2004

19. Ditor DS, Macdonald MJ, Kamath MV, Bugaresti J, Adams M, McCartney N, Hicks AL. The effects of body-weight supported treadmill training on cardiovascular regulation in individuals with motor-complete SCI. Spinal Cord. 2005; 43(11):664-73. [PMID:15968298] http://dx.doi.org/10.1038/sj.sc.3101785

20. Phillips SM, Stewart BG, Mahoney DJ, Hicks AL, McCartney N, Tang JE, Wilkinson SB, Armstrong D, Tarnopolsky MA. Body-weight-support treadmill training improves blood glucose regulation in persons with incomplete spinal cord injury. J Appl Physiol. 2004;97(2):716-24.

[PMID:15107410]

http://dx.doi.org/10.1152/japplphysiol.00167.2004

21. Soyupek F, Savas S, Oztürk O, Ilgün E, Bircan A, Akkaya A. Effects of body weight supported treadmill training on cardiac and pulmonary functions in the patients with incomplete spinal cord injury. J Back Musculoskelet Rehabil. 2009;22(4):213-18. [PMID:20023352]

22. Hidler J, Hamm LF, Lichy A, Groah SL. Automating activity-based interventions: The role of robotics. J Rehabil Res Dev. 2008;45(2):337-44. [PMID:18566951] http://dx.doi.org/10.1682/JRRD.2007.01.0020

23. Israel JF, Campbell DD, Kahn JH, Hornby TG. Metabolic costs and muscle activity patterns during robotic- and therapist-assisted treadmill walking in individuals with incomplete spinal cord injury. Phys Ther. 2006;86(11):1466-78. [PMID:17079746] http://dx.doi.org/10.2522/ptj.20050266

24. Jack LP, Purcell M, Allan DB, Hunt KJ. The metabolic cost of passive walking during robotics-assisted treadmill exercise. Technol Health Care. 2011;19(1):21-27. [PMID:21248409]

25. Turiel M, Sitia S, Cicala S, Magagnin V, Bo I, Porta A, Caiani E, Ricci C, Licari V, De Gennaro Colonna V, Tomasoni L. Robotic treadmill training improves cardiovascular function in spinal cord injury patients. Int J Cardiol. 2011; 149(3):323-29. [PMID:20219258] http://dx.doi.org/10.1016/j.ijcard.2010.02.010

26. Cai LL, Fong AJ, Otoshi CK, Liang Y, Burdick JW, Roy RR, Edgerton VR. Implications of assist-as-needed robotic step training after a complete spinal cord injury on intrinsic strategies of motor learning. J Neurosci. 2006;26(41): 10564-68. [PMID:17035542] http://dx.doi.org/10.1523/JNEUROSCI.2266-06.2006

27. Ziegler MD, Zhong H, Roy RR, Edgerton VR. Why variability facilitates spinal learning. J Neurosci. 2010;30(32): 10720-26. [PMID:20702702] http://dx.doi.org/10.1523/JNEUROSCI.1938-10.2010

28. Kirshblum SC, Waring W, Biering-Sorensen F, Burns SP, Johansen M, Schmidt-Read M, Donovan W, Graves D, Jha A, Jones L, Mulcahey MJ, Krassioukov A. Reference for the 2011 revision of the International Standards for Neurological Classification of Spinal Cord Injury. J Spinal Cord Med. 2011;34(6):547-54. [PMID:22330109] http://dx.doi.org/10.1179/107902611X13186000420242

29. Dobkin BH. Progressive staging of pilot studies to improve phase III trials for motor interventions. Neurorehabil Neural Repair. 2009;23(3):197-206. [PMID:19240197] http://dx.doi.org/10.1177/1545968309331863

30. Meijer JH, Boesveldt S, Elbertse E, Berendse HW. Method to measure autonomic control of cardiac function using time 
interval parameters from impedance cardiography. Physiol Meas. 2008;29(6):S383-91. [PMID:18544834]

http://dx.doi.org/10.1088/0967-3334/29/6/S32

31. Thompson WR, Gordon NF, Pescatello LS; American College of Sports Medicine. ACSM's guidelines for exercise testing and prescription. 8th ed. Philadelphia (PA): Lippincott Williams \& Wilkins; 2010.

32. Hopman MT, Dueck C, Monroe M, Philips WT, Skinner JS. Limits to maximal performance in individuals with spinal cord injury. Int J Sports Med. 1998;19(2):98-103.

PMID:9562217] http://dx.doi.org/10.1055/s-2007-971889

33. Magel JR, McArdle WD, Toner M, Delio DJ. Metabolic and cardiovascular adjustment to arm training. J Appl Physiol. 1978;45(1):75-79. [PMID:670036]

34. Sawka MN, Foley ME, Pimental NA, Toner MM, Pandolf KB. Determination of maximal aerobic power during upper-body exercise. J Appl Physiol. 1983;54(1):113-17. [PMID:6826395]

35. Ginis KA, Hicks AL, Latimer AE, Warburton DE, Bourne C, Ditor DS, Goodwin DL, Hayes KC, McCartney N, McIlraith A, Pomerleau P, Smith K, Stone JA, Wolfe DL. The development of evidence-informed physical activity guidelines for adults with spinal cord injury. Spinal Cord. 2011;49(11):1088-96. [PMID:21647164]

http://dx.doi.org/10.1038/sc.2011.63

36. van den Berg R, de Groot S, Swart KM, van der Woude LH. Physical capacity after 7 weeks of low-intensity wheelchair training. Disabil Rehabil. 2010;32(26):2244-52. [PMID:21110694] http://dx.doi.org/10.3109/09638288.2010.535688

37. Haskell WL. J.B. Wolffe Memorial Lecture. Health consequences of physical activity: Understanding and challenges regarding dose-response. Med Sci Sports Exerc. 1994; 26(6):649-60. [PMID:8052103] http://dx.doi.org/10.1249/00005768-199406000-00001
38. Jack LP, Allan DB, Hunt KJ. Cardiopulmonary exercise testing during body weight supported treadmill exercise in incomplete spinal cord injury: A feasibility study. Technol Health Care. 2009;17(1):13-23. [PMID:19478401]

39. Hunt KJ, Jack LP, Pennycott A, Perret C, Baumberger M, Kakebeeke TH. Control of work rate-driven exercise facilitates cardiopulmonary training and assessment during robot-assisted gait in incomplete spinal cord injury. Biomed Signal Process Control. 2008;3(1):19-28. http://dx.doi.org/10.1016/j.bspc.2007.10.002

40. Jack LP, Purcell M, Allan DB, Hunt KJ. Comparison of peak cardiopulmonary performance parameters during robotics-assisted treadmill exercise and arm crank ergometry in incomplete spinal cord injury. Technol Health Care. 2010;18(4-5):285-96. [PMID:21209477]

41. Compher C, Frankenfield D, Keim N, Roth-Yousey L; Evidence Analysis Working Group. Best practice methods to apply to measurement of resting metabolic rate in adults: A systematic review. J Am Diet Assoc. 2006;106(6):881-903. [PMID:16720129] http://dx.doi.org/10.1016/j.jada.2006.02.009

Submitted for publication October 17, 2012. Accepted in revised form May 30, 2013.

This article and any supplementary material should be cited as follows:

Hoekstra F, van Nunen MP, Gerrits KH, Stolwijk-Swüste JM, Crins MH, Janssen TW. Effect of robotic gait training on cardiorespiratory system in incomplete spinal cord injury. J Rehabil Res Dev. 2013;50(10):1411-22. http://dx.doi.org/10.1682/JRRD.2012.10.0186

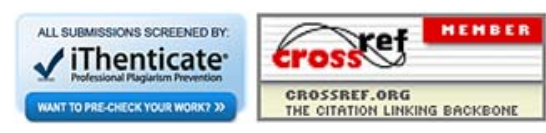

